\title{
A Study on Quality of Life and Cognitive Impairment in Hepatitis C Positive Patients Receiving Interferon Therapy
}

\author{
Dr. Karanjot Kaur ${ }^{1}$, Dr. Anuj Sharma ${ }^{2}$, Dr. Ranjive Mahajan ${ }^{3 *}$
}

${ }^{1,2}$ PG Resident Psychiatry, DMC\&H Ludhiana, India

${ }^{3}$ Head \& Professor, DMC\&H Ludhiana, India

DOI: $10.36347 /$ sjams.2020.v08i07.020

| Received: 10.07.2020 | Accepted: 18.07.2020 | Published: 21.07.2020

*Corresponding author: Dr. Ranjive Mahajan

\section{Abstract}

Original Research Article

Background: An association between hepatitis $\mathrm{C}$ virus infection and neuropsychiatric symptoms has been proposed for some years. These symptoms include affective \& behavioral components that are sometimes not easily distinguished from each other. Chronic infection with hepatitis $\mathrm{C}$ virus (HCV) has a profound effect on health-related quality of life- with fatigue, depression and neurocognitive deficits among the most common complaints. Aim: To study of Quality of life and cognitive impairment in Hepatitis C positive patients receiving Interferon Therapy. Material and methods: The clinical study was conducted on 60 patients with chronic Hepatitis $\mathrm{C}$ infection. The patients were drawn from Gastroenterology Deptt. (OPD \& indoor) and patients referred to Psychiatry Department for assessment. There were divided into two groups (A \& B). Group A included cases who were hepatitis C +ve and were on Interferon therapy Group B included controls who were Hepatitis C +ve and not on Interferon therapy. Cognitive assessment and QOL was assessed by using socio demographic profile, cognitive functioning scale and quality of life questionnaire. Results: In hepatitis C patients on Peg- IFN therapy (Group A) , cognitive functioning was highly significantly impaired from baseline to 12 weeks as compared to patients not on Peg -IFN therapy (Group B) (P $=0.001$ ). Also, in Group A, there was highly significant worsening in physical as well as psychological component of QOL questionnaire from baseline to 12 weeks as compared to Group B $(\mathrm{P}=0.000)$. Conclusions: There is a significant impairment in cognitive functions and quality of life in Hepatitis C patients on Peg-interferon therapy.

Keywords: cognition, interferon therapy, hepatitis-C.

Copyright @ 2020: This is an open-access article distributed under the terms of the Creative Commons Attribution license which permits unrestricted use, distribution, and reproduction in any medium for non-commercial use (NonCommercial, or CC-BY-NC) provided the original author and source are credited.

\section{INTRODUCTION}

Cognition refers to a set of vastly complex processes, such as language, problem solving and thinking that apply plans and strategies to sensations and perceptions [1]. Cognitive process has different domains that include episodic memory, working or immediate memory, vigilance or sustained attention, executive functioning, verbal fluency, early visual processing, psychomotor skills, language and verbal knowledge, speed of processing [2].

Cognitive disorders exemplify the complex interface between neurology, medicine \& psychiatry as medical or neurological conditions often lead to cognitive disorders that are in term, associated with behavioral symptoms [4].

World Health Organization began a project in 1991 to define and create a measure for Quality of Life (QOL) in such a way so as to allow inputs from a broad range of cultures around the world. World Health
Organization stated that QOL is affected by the condition of life resulting from combination of the effects of the complete range of factors such as those determining health, happiness (including comfort in the physical environment and a satisfying occupation), education, social and intellectual attainments, freedom of action, justice and freedom of expression". QOL is a broad ranging concept affected in a complex way by the person's physical health, psychological state, level of independence, social relationships and their relationships to salient features of their environment [4].

Chronic Hepatitis $\mathrm{C}$ is an infectious disease and a major cause of chronic liver disease worldwide. Therapy for Hepatitis $\mathrm{C}$ is still unsatisfactory, although at present, a sustained loss of Hepatitis $\mathrm{C}$ virus can be achieved in about $50 \%$ of patients treated with a combination therapy of peg- interferon Alfa \& Ribavirin up to maximum of one year [5]. 
Neuropsychiatric symptoms frequently occur in Hepatitis C patients treated with interferon - Alfa. These symptoms include affective \& behavioral components that are sometimes not easily distinguished from each other. Various studies have been done to assess interferon induced neurocognitive side effects \& quality of life of Hepatitis $\mathrm{C}$ patients on this therapy but the results available are inconsistent [6].

In a prospective longitudinal study on Hepatitis $C$ patients receiving interferon alfa therapy it was found that there was significant increase in the incidence of depression, anxiety, anger and hostility. The cumulative frequency of clinically relevant emotional distress (depression, anxiety, or anger and hostility) during Interferon alfa therapy was $57.7 \%$ as compared with $22.5 \%$ before therapy. However, Interferon - alfa therapy had to be stopped prematurely because of untreatable psychiatric symptoms in only $8.3 \%$ of patients [7].

Another study concluded that patients with chronic Hepatitis C or compensated cirrhosis showed a decrease in Quality of Life in spite of unimpaired neuropsychological tests. Patients with decompensated cirrhosis, the decrease in quality of life was associated with the severity of liver failure, neuropsychological abnormalities and treatment with beta-blockers or diuretics. However, in the multivariable analysis only treatment with beta-blockers or diuretics was independently associated with quality of life. The mechanisms that worsen quality of life are unknown [8].

Cognitive changes associated with Interferon therapy include impaired concentration, decreased alertness, deficits in verbal memory and mental slowing. Reduced alertness and slowed reactions have been reported in healthy volunteers after only a single dose of Interferon therapy [9].

Cognitive deficits persist after treatment discontinuation. In a retrospective study of 14 patients, 12 of whom had discontinued treatment because of neurotoxicity, all had evidence of persistent neurotoxic deficits and 10 showed symptoms consistent with frontal-subcortical dysfunction[10].

Four patients demonstrated a more generalized decline of Cognitive function. In Some studies have reported resolution of symptoms within 2-3 weeks after discontinuation of Interferon.

There is also data that patients with Hepatitis C receiving Interferon - alfa therapy showed a significant but reversible impairment of neurocognitive performance. Reaction time was significantly increased during treatment. ${ }^{(5)}$ Cognitive function does not worsen during long-term low dose peg interferon therapy in patients with chronic Hepatitis C. Cognitive function is neither influenced by low dose Peg - Interferon treatment nor with evidence of disease progression in patients with advanced chronic Hepatitis C prospectively followed up for $3.5 \mathrm{yrs}$ [11].

According to a prospective study of chronic Hepatitis C patients treated with Peg -Interferon and Ribavirin it was found that retreatment of prior nonresponders with peg interferon and Ribavirin was not associated with objective evidence of cognitive impairment as measured by a comprehensive battery of neuropsychological tests [12]. Due to inconsistent results, this study was done to assess the impact of PegInterferon therapy on Cognitive function \& quality of life of Hepatitis C patients.

\section{Material \& Methods Sample}

The study was conducted in the Deptt. of Psychiatry, DMC \& H, Ludhiana on 60 subjects with chronic Hepatitis $\mathrm{C}$ infection.

The patients were drawn from Gastroenterology Deptt. (OPD \& indoor) and patients referred to Psychiatry Deptt. for assessment.

\section{Recruitment of Subjects}

- There were 60 subjects who were divided into two groups (A \& B).

- Group A included cases who were hepatitis $\mathrm{C}+\mathrm{ve}$ and were on Interferon therapy.

- Group B included controls who were Hepatitis $\mathrm{C}+\mathrm{ve}$ and not on Interferon therapy.

\section{Inclusion Criteria (Group A and Group B)}

- Age 18-65 years of either gender

- Subjects who were cooperative were included.

- Subjects who gave written informed Consent were included.

\section{Exclusion Criteria (Group A and Group B)}

Those subjects having co morbid unstable medical \& surgical illness were excluded. Subjects with preexisting psychiatric disorder including alcohol dependence were excluded. Hepatitis C patients with coexisting HIV \& Hepatitis B+ve illness were excluded.

\section{TOOLS}

1. Socio-demographic profile

2. Cognitive functioning scale

3. Quality of life questionnaire 


\section{RESULTS}

Table-1: Distribution of Hepatitis- $\mathrm{C}$ patients in various groups

\begin{tabular}{|l|c|c|}
\hline GROUPS & CASES & CONTROLS \\
\hline HEPATITIS - C patients & Patients on Peg-Interferon therapy & Patients not on Peg-Interferon therapy \\
\hline Total no. of patients $=60$ & 30 & 30 \\
\hline
\end{tabular}

Table-2: Socio Demographic Variables According to age distribution of patients

\begin{tabular}{|c|c|c|c|c|c|}
\hline Age (years) & \multicolumn{2}{|c|}{ Cases } & \multicolumn{2}{|c|}{ Control } & \multirow[t]{2}{*}{ t-value } \\
\hline & No. & $\%$ age & No. & \%age & \\
\hline$<=30$ & 7 & 23.33 & 9 & 30.00 & \multirow{5}{*}{0.54} \\
\hline $31-40$ & 11 & 36.67 & 5 & 16.67 & \\
\hline $41-50$ & 5 & 16.67 & 8 & 26.67 & \\
\hline $51-60$ & 6 & 20.00 & 4 & 13.33 & \\
\hline$>60$ & 1 & 3.33 & 4 & 13.33 & \\
\hline Mean \pm S.D. & \multicolumn{2}{|c|}{$40.37 \pm 11.22$} & \multicolumn{2}{|c|}{$42.13 \pm 13.89$} & \\
\hline p-value & \multicolumn{4}{|c|}{0.306} & \\
\hline
\end{tabular}

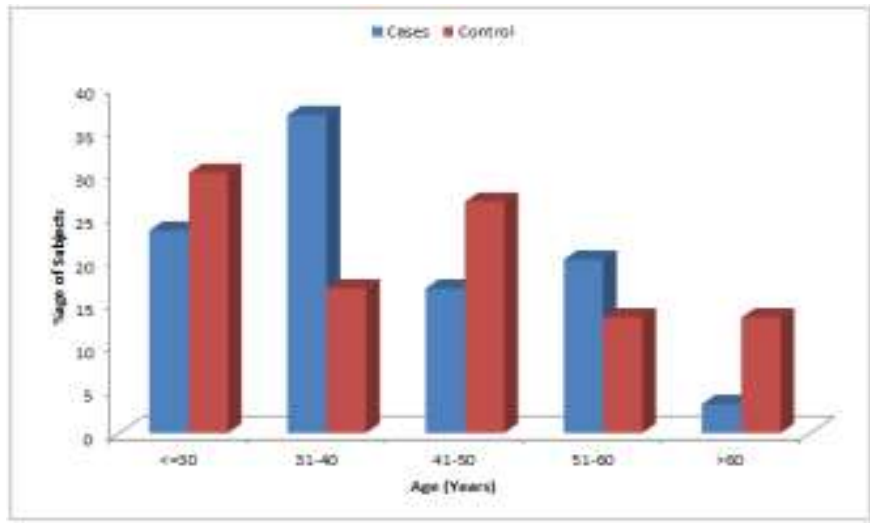

Graph-1: According to Age distribution of Patients $.306)$.

Applying unpaired t-test. The variation in age was not found to be non significant between two groups $(P=$

Table-3: According to gender distribution of patients

\begin{tabular}{|l|c|c|c|c|c|}
\hline \multirow{2}{*}{ Sex } & \multicolumn{2}{|c|}{ Cases } & \multicolumn{2}{c|}{ Control } & \multirow{2}{*}{ Chi-square } \\
\cline { 2 - 5 } & No. & \% age & No. & \% age & \\
\hline Male & 18 & 60.00 & 19 & 63.33 & \multirow{2}{*}{0.07} \\
\hline Female & 12 & 40.00 & 11 & 36.67 & \\
\hline p-value & \multicolumn{4}{|c|}{0.621} & \\
\hline
\end{tabular}

Significant $=(P<0.05)$ $0.621)$.

On comparing of two groups, there was non-significant difference in distribution on the basis of gender $(P=$

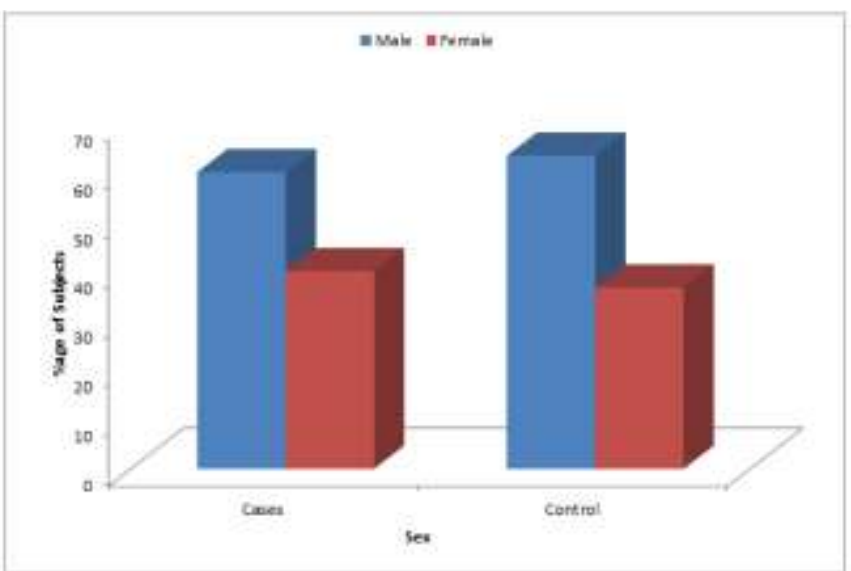

Graph-2: According to Gender distribution of patients 
No significant difference in distribution on the basis of gender was seen $(P=0.621)$. According to level of education of patient-
No significant difference in the distribution on the basis of level of education of patients $(P=0.124)$.

Table-4: According to type of virus of Hepatitis -c +ve patients-

\begin{tabular}{|l|c|c|c|c|c|c|}
\hline \multirow{2}{*}{ Diagnosis } & \multicolumn{2}{|c|}{ Cases } & \multicolumn{2}{c|}{ Control } & \multirow{2}{*}{ p-value } & \multirow{2}{*}{ Z-value } \\
\cline { 2 - 5 } & No. & \%age & No. & \%age & & \\
\hline HCV - 1 & 1 & 3.33 & 3 & 10.00 & 0.159 & 1.04 \\
\hline HCV - 3 & 28 & 93.33 & 27 & 90.00 & 0.353 & 0.47 \\
\hline HCV - 1,4 & 1 & 3.33 & 0 & 0.00 & 0.164 & 1.01 \\
\hline
\end{tabular}

Significant $=(P<0.05)$

There was no significant difference in the distribution of patients according to type of Hepatitis $\mathrm{C}$ virus between two groups

\section{Cognitive Functioning Impairement in intra group}

Paired t- test was applied \& it was observed that CF was highly significantly impaired in Hepatitis$\mathrm{C}$ patients on Peg - IFN therapy (cases) from baseline to 12 weeks $(\mathrm{P}=0.001 * *)$,

Table-5

\begin{tabular}{|l|c|c|c|}
\hline \multirow{2}{*}{ Cognitive functioning impairment } & Cases & \multirow{2}{*}{ t-value } & \multirow{2}{*}{ p-value } \\
\cline { 2 - 2 } & Mean \pm SD & & \\
\hline Baseline & $1.53 \pm 0.97$ & \multirow{2}{*}{5.18} & \multirow{2}{*}{$0.001^{* *}$} \\
\hline Followup & $5.30 \pm 0.65$ & & \\
\hline
\end{tabular}

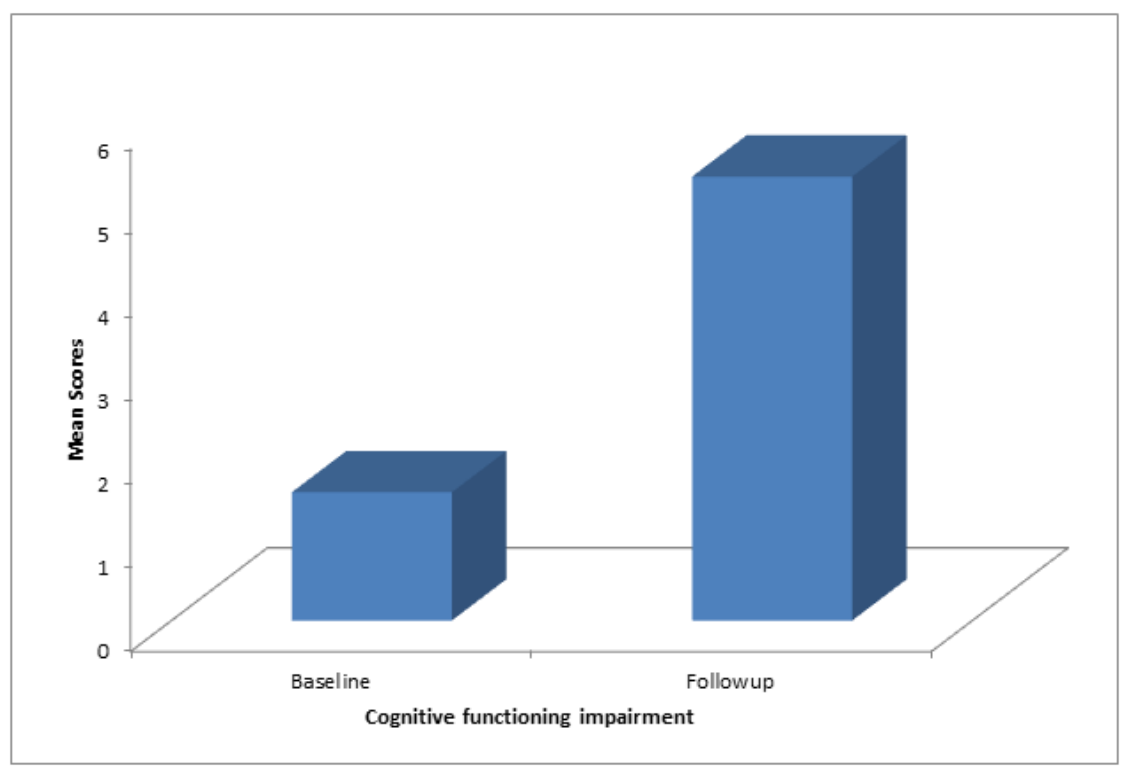

Graph-3: Cognitive functioning impairment

Cognitive functioning impairment between Group A vs Group B (cases vs controls) CFS was applied on both the groups (A \& B) at baseline \& then at follow up (12 weeks ).

\begin{tabular}{|l|c|c|c|c|}
\hline \multirow{2}{*}{ Cognitive functioning impairment } & Cases & Control & \multirow{2}{*}{ p-value } & \multirow{2}{*}{ t-value } \\
\cline { 2 - 5 } & Mean \pm SD & Mean \pm SD & & \\
\hline Baseline & $1.53 \pm 0.97$ & $1.37 \pm 0.67$ & 0.222 & 0.74 \\
\hline Follow up & $5.30 \pm 0.65$ & $1.57 \pm 0.49$ & $0.0001 *$ & 25.10 \\
\hline
\end{tabular}

It was observed that there was no significant change in $\mathrm{CF}$ at baseline between two groups. $(\mathrm{P}=$ 0.222 ), but there was a highly significant impairment in
$\mathrm{CF}$ at 12 weeks between two groups. $\left(\mathrm{P}=0.0001^{* *}\right.$. i.e. Group A was more cognitively impaired at 12 weeks. 


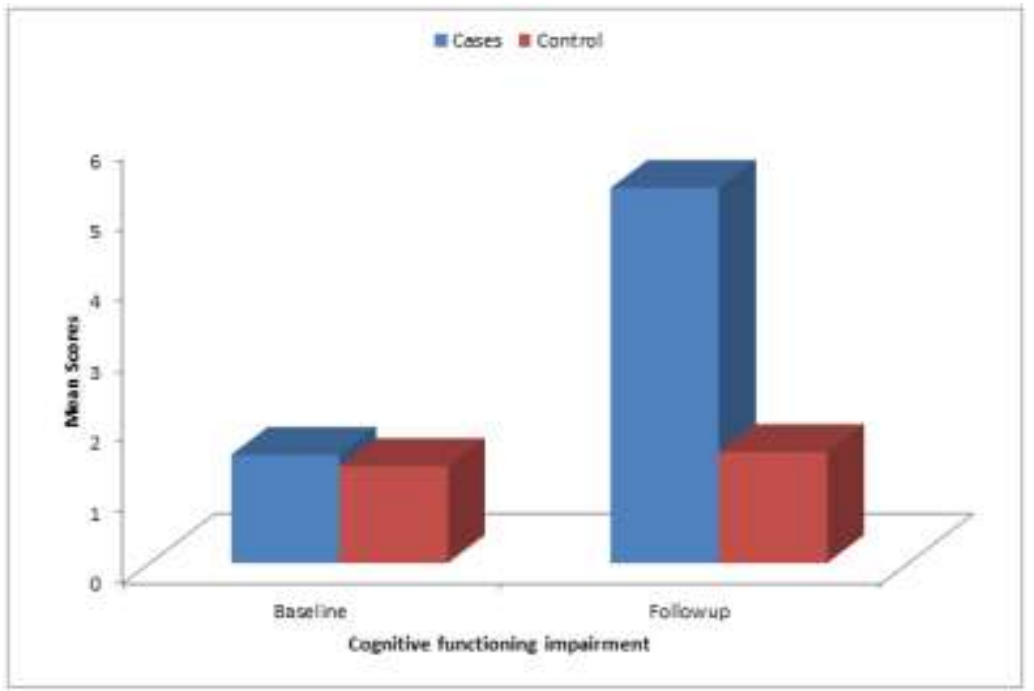

Graph-4: Cognitive functioning changes between two groups (cases \& controls)

Quality of Life Questionnaire (QOL Physical Component) in Group A (Cases) \& Group B (Controls) QOL questionnaire was applied in group A at baseline $\&$ at follow up (12 weeks) \& , It was observed that there was highly significant change in physical component of QOL in Cases $\left(\mathrm{P}=0.000^{* *}\right)$, with the physical component worsening from baseline to 12 weeks.

Table-6: Physical component

\begin{tabular}{|l|c|c|c|c|}
\hline QOL item no. & Baseline & Followup & t- value & p-value \\
\hline 1. & $2.67 \pm 0.92$ & $1.40 \pm 1.52$ & 4.68 & $0.000^{* *}$ \\
\hline 2. & $3.47 \pm 0.90$ & $2.43 \pm 1.10$ & 5.48 & $0.000^{* *}$ \\
\hline 3. & $1.50 \pm 1.53$ & $2.80 \pm 0.76$ & 2.97 & $0.006^{* *}$ \\
\hline 4. & $2.80 \pm 0.76$ & $2.40 \pm 1.22$ & 1.68 & 0.103 \\
\hline 5. & $2.90 \pm 0.55$ & $2.70 \pm 0.92$ & 1.44 & 0.161 \\
\hline 6. & $3.00 \pm 0.00$ & $3.00 \pm 0.00$ & NA & NA \\
\hline 7. & $3.00 \pm 0.00$ & $2.80 \pm 0.76$ & 1.44 & 0.161 \\
\hline 8. & $2.90 \pm 0.55$ & $3.00 \pm 0.00$ & 1.00 & 0.326 \\
\hline 9. & $3.00 \pm 0.00$ & $3.00 \pm 0.00$ & NA & NA \\
\hline 10. & $3.00 \pm 0.00$ & $3.00 \pm 0.00$ & NA & NA \\
\hline Score & $\mathbf{2 8 . 1 7 \pm 2 . 7 2}$ & $\mathbf{2 4 . 6 0 \pm 2 . 9 4}$ & $\mathbf{7 . 9 4}$ & $\mathbf{0 . 0 0 0} * *$ \\
\hline
\end{tabular}

$(\mathrm{P}<0.01)=$ Highly significant, $(\mathrm{P}<0.05)=$ Significant

There is highly significant change in physical component of Quality of life in Cases $\left(\mathrm{P}=0.000^{* *}\right)$.

QOL questionnaire was applied in group B at baseline $\&$ at follow up (12 weeks), It was observed that there was a highly significant change in physical component of QOL in Controls $\left(\mathrm{P}=0.000^{* *}\right)$, with the physical component worsening from baseline to 12 weeks

Table-7: Physical component

\begin{tabular}{|l|c|c|c|c|}
\hline QOL item no. & Baseline & Followup & t-value & p-value \\
\hline 1. & $2.50 \pm 1.14$ & $2.00 \pm 1.44$ & 2.41 & 0.023 \\
\hline 2. & $4.30 \pm 0.70$ & $3.53 \pm 0.51$ & 6.19 & 0.000 \\
\hline 3. & $0.80 \pm 1.35$ & $2.10 \pm 1.40$ & 2.97 & 0.006 \\
\hline 4. & $2.80 \pm 0.76$ & $2.50 \pm 1.14$ & 1.36 & 0.184 \\
\hline 5. & $3.00 \pm 0.00$ & $2.60 \pm 1.04$ & 2.11 & 0.043 \\
\hline 6. & $3.00 \pm 0.00$ & $2.60 \pm 1.04$ & 2.11 & 0.043 \\
\hline 7. & $3.00 \pm 0.00$ & $2.70 \pm 0.92$ & 1.80 & 0.083 \\
\hline 8. & $2.90 \pm 0.55$ & $2.70 \pm 0.92$ & 1.00 & 0.0326 \\
\hline 9. & $3.00 \pm 0.00$ & $2.90 \pm 0.55$ & 1.00 & 0.326 \\
\hline 10. & $3.00 \pm 0.00$ & $2.90 \pm 0.55$ & 1.00 & 0.326 \\
\hline Score & $\mathbf{3 0 . 4 7 \pm 1 . 5 7}$ & $\mathbf{2 6 . 3 7} \pm \mathbf{3 . 2 1}$ & $\mathbf{8 . 6 2}$ & $\mathbf{0 . 0 0 0} * *$ \\
\hline \multicolumn{4}{|l}{$(\mathrm{P}<0.01)$} \\
\hline
\end{tabular}

$(\mathrm{P}<0.01)=$ Highly significant, $(\mathrm{P}<0.05)=$ Significant

There is highly significant change in physical component of Quality of life in Controls $(\mathrm{P}=0.000 * *)$. 


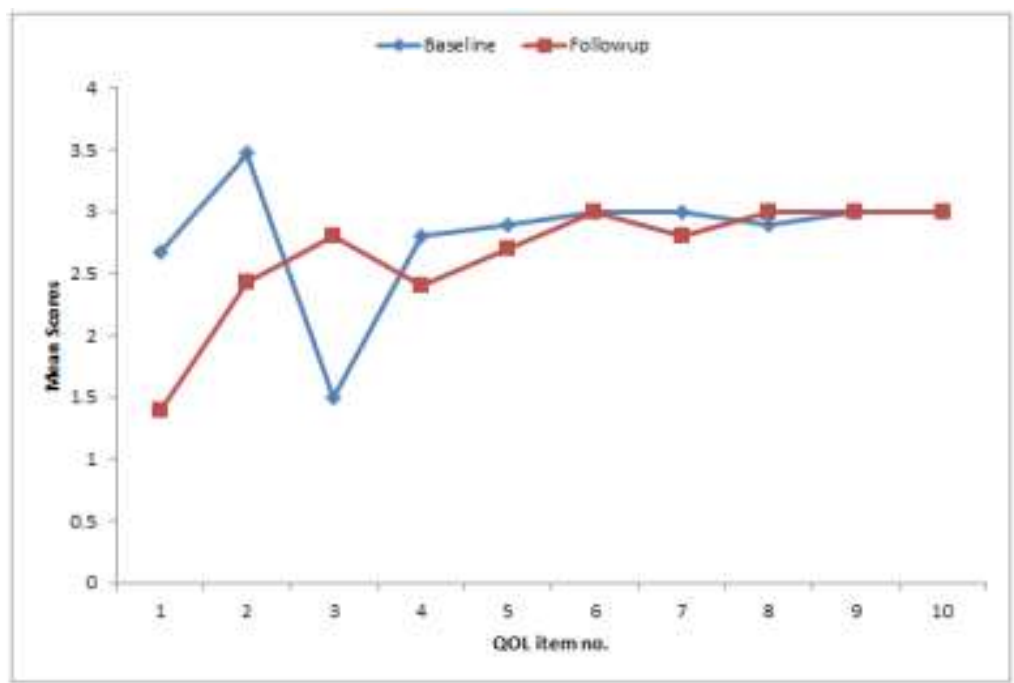

Graph-5: Quality of life questionnaire (QOL Physical component) in Cases

Quality of Life Questionnaire (QOL Psychological Component) in Group A \& Group B

QOL questionnaire was applied to group A at baseline $\&$ at follow up (12 weeks) \& psychological component was assessed at both stages. It was observed that there was a highly significant change in psychological component of QOL in Cases $(\mathrm{P}=$ $0.000 * *)$ with the psychological component worsening from baseline to 12 weeks.

Table-8: Psychological Component

\begin{tabular}{|c|c|c|c|c|}
\hline QOL (Item no.) & Baseline & Followup & t-value & p-value \\
\hline 1. & $3.57 \pm 0.94$ & $2.30 \pm 0.84$ & 8.84 & $0.000^{* *}$ \\
\hline 2. & $3.67 \pm 0.61$ & $2.57 \pm 0.82$ & 12.54 & $0.005^{* *}$ \\
\hline 3. & $4.40 \pm 0.77$ & $3.67 \pm 0.96$ & 3.00 & $0.000 * *$ \\
\hline 4. & $4.03 \pm 0.85$ & $2.87 \pm 0.78$ & 7.00 & $0.000 * *$ \\
\hline 5. & $3.63 \pm 0.81$ & $2.67 \pm 0.76$ & 5.95 & $0.000 * *$ \\
\hline 6. & $3.20 \pm 0.85$ & $2.43 \pm 0.63$ & 5.77 & $0.000 * *$ \\
\hline 7. & $3.53 \pm 0.78$ & $2.47 \pm 0.57$ & 11.22 & $0.000^{* *}$ \\
\hline 8. & $3.67 \pm 0.96$ & $2.70 \pm 0.79$ & 4.46 & $0.002 * *$ \\
\hline 9. & $3.27 \pm 0.69$ & $2.73 \pm 0.64$ & 3.40 & $0.004 * *$ \\
\hline 10. & $3.90 \pm 0.99$ & $3.30 \pm 0.47$ & 3.17 & $0.000 * *$ \\
\hline 11. & $4.37 \pm 0.56$ & $3.07 \pm 1.08$ & 9.50 & $0.000 * *$ \\
\hline 12. & $3.17 \pm 1.02$ & $2.10 \pm 1.06$ & 4.65 & 0.000 ** \\
\hline 13. & $3.40 \pm 0.89$ & $2.20 \pm 0.81$ & 10.77 & $0.000 * *$ \\
\hline 14. & $3.97 \pm 0.81$ & $2.70 \pm 1.24$ & 8.38 & $0.012 * *$ \\
\hline 15. & $2.47 \pm 1.20$ & $1.87 \pm 1.07$ & 2.69 & $0.000 * *$ \\
\hline 16. & $3.23 \pm 0.73$ & $2.30 \pm 0.75$ & 7.39 & 0.000 ** \\
\hline 17. & $3.53 \pm 1.14$ & $2.23 \pm 1.07$ & 6.36 & $0.000 * *$ \\
\hline 18. & $3.63 \pm 0.72$ & $2.40 \pm 1.22$ & 8.27 & $0.000^{* *}$ \\
\hline 19. & $3.27 \pm 0.64$ & $2.27 \pm 0.94$ & 5.79 & $0.000 * *$ \\
\hline 20. & $2.83 \pm 0.95$ & $2.00 \pm 0.69$ & 5.22 & 0.573 \\
\hline 21. & $1.93 \pm 1.44$ & $2.07 \pm 0.83$ & 0.57 & $0.000 * *$ \\
\hline 22. & $3.70 \pm 0.88$ & $2.47 \pm 1.04$ & 5.52 & $0.000 * *$ \\
\hline Score & $76.40 \pm 11.85$ & $55.33 \pm 11.56$ & 13.51 & $\mathbf{0 . 0 0 0} * *$ \\
\hline
\end{tabular}

$(\mathrm{P}<0.01)=$ Highly significant

$(\mathrm{P}<0.05)=$ Significant

There is highly significant change in psychological component of Quality of life in Cases $\left(\mathrm{P}=0.000^{* *}\right)$. 


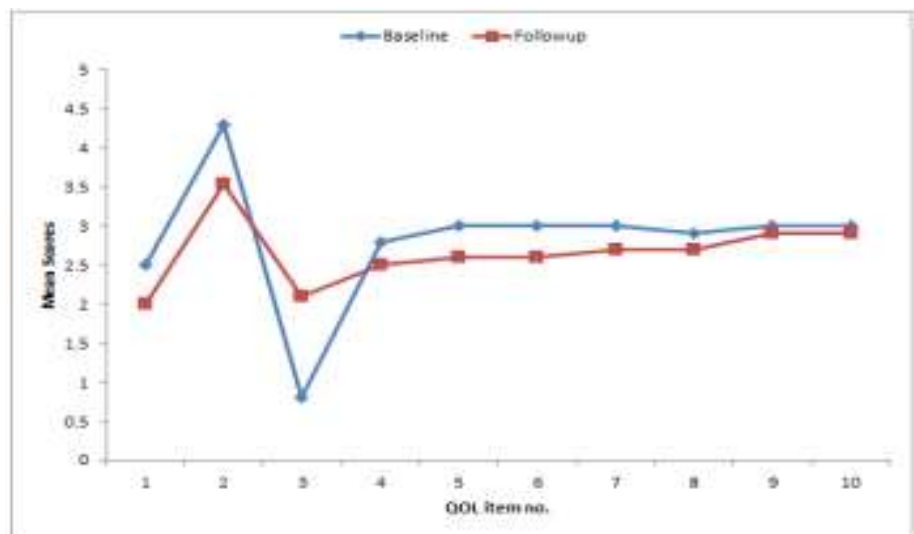

Graph-6: Quality of life questionnaire (QOL Physical Component) in Controls

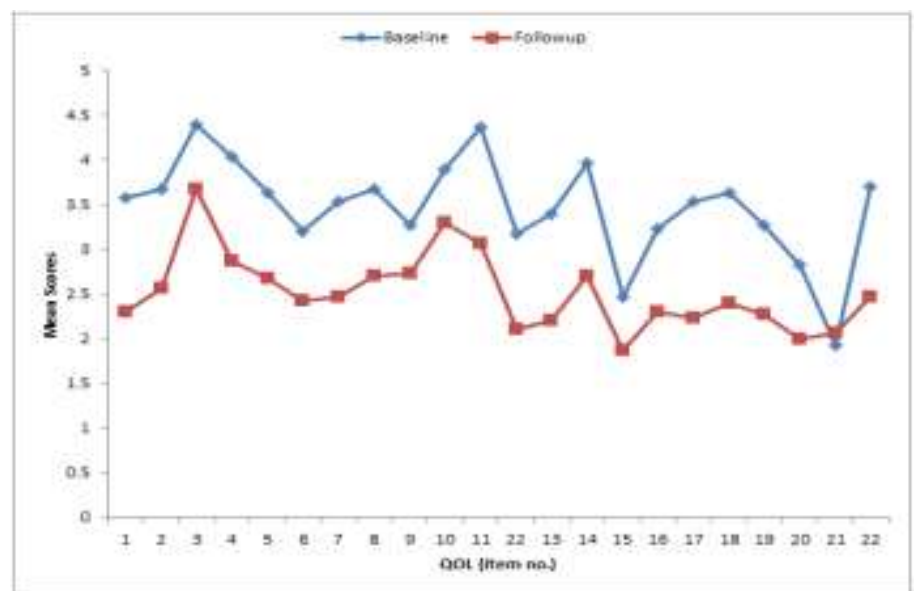

Graph-7: Quality of life questionnaire (QOL Psychological Component) in Cases (Controls)

It was observed that there was a highly significant change in psychological component of QOL
$\left(\mathrm{P}=0.000^{* *}\right)$ with, worsening from baseline to 12 weeks.

Psychological Component

\begin{tabular}{|l|c|c|c|c|}
\hline QOL (Item no.) & Baseline & Followup & t-value & p-value \\
\hline 1. & $3.80 \pm 1.03$ & $3.40 \pm 0.72$ & 2.26 & $0.031^{*}$ \\
\hline 2. & $3.90 \pm 0.88$ & $3.47 \pm 0.78$ & 2.90 & $0.007^{* *}$ \\
\hline 3. & $3.73 \pm 0.78$ & $3.43 \pm 0.68$ & 2.34 & $0.026^{*}$ \\
\hline 4. & $3.77 \pm 0.82$ & $3.40 \pm 0.81$ & 2.08 & $0.046^{*}$ \\
\hline 5. & $3.73 \pm 0.74$ & $3.20 \pm 0.96$ & 2.50 & $0.018^{*}$ \\
\hline 6. & $3.63 \pm 0.76$ & $3.17 \pm 0.75$ & 2.54 & $0.017^{*}$ \\
\hline 7. & $3.53 \pm 0.82$ & $3.17 \pm 0.79$ & 2.63 & $0.014^{*}$ \\
\hline 8. & $3.43 \pm 0.97$ & $3.07 \pm 0.74$ & 2.36 & 0.025 \\
\hline 9. & $3.43 \pm 0.82$ & $3.00 \pm 0.69$ & 2.90 & $0.007 * *$ \\
\hline 10. & $3.60 \pm 0.86$ & $3.23 \pm 0.86$ & 2.48 & 0.019 \\
\hline 11. & $3.53 \pm 0.90$ & $3.17 \pm 0.99$ & 2.01 & 0.054 \\
\hline 12. & $3.67 \pm 0.99$ & $3.33 \pm 0.92$ & 0.102 & 0.077 \\
\hline 13. & $3.67 \pm 1.03$ & $3.27 \pm 0.74$ & 1.84 & 0.050 \\
\hline 14. & $3.77 \pm 0.94$ & $3.30 \pm 0.79$ & 2.05 & 0.032 \\
\hline 15. & $3.77 \pm 0.90$ & $3.37 \pm 0.85$ & 2.25 & 0.050 \\
\hline 16. & $3.57 \pm 0.94$ & $3.13 \pm 0.94$ & 2.05 & 0.025 \\
\hline 17. & $3.80 \pm 0.71$ & $3.20 \pm 0.85$ & 2.36 & $0.004^{* *}$ \\
\hline 18. & $3.60 \pm 0.86$ & $3.23 \pm 0.82$ & 3.17 & 0.102 \\
\hline 19. & $3.90 \pm 0.92$ & $3.37 \pm 0.96$ & 1.69 & $0.0058^{* *}$ \\
\hline 20. & $3.73 \pm 0.74$ & $3.23 \pm 0.73$ & 3.75 & $0.001^{* *}$ \\
\hline 21. & $3.53 \pm 0.90$ & $3.07 \pm 0.83$ & 3.12 & $0.004^{* *}$ \\
\hline 22. & $3.57 \pm 0.97$ & $3.03 \pm 0.85$ & 3.57 & $0.001^{* *}$ \\
\hline Score & $\mathbf{8 0 . 8 3 \pm \mathbf { 1 0 . 4 4 }}$ & $\mathbf{7 1 . 0 7 \pm \mathbf { 1 0 . 1 4 }}$ & $\mathbf{4 . 6 6}$ & $\mathbf{0 . 0 0 0 * *}$ \\
\hline
\end{tabular}

$(\mathrm{P}<0.01)=$ Highly significant, $(\mathrm{P}<0.05)=$ Significant

There is highly significant change in psychological component of Quality of life in Controls $(\mathrm{P}=0.000 * *)$. 


\section{DISCUSSION}

In this study 60 subjects who were Hepatitis C positive were included coming to Psychiatry \& Gastroenterology (OPD \& indoor) and patients referred to Psychiatry Department for assessment.

A study done in Germany on chronic Hepatitis $\mathrm{C}$ pt. found that pt. that were started on IFN -alfa therapy had significant impairment in cognitive functioning after 12 weeks of IFN therapy \& that might be related to functional disturbances in the prefrontal cortex and hippocampus. It was also concluded that impairment in $\mathrm{CF}$ also affects patient's mental health and QOL [1].

Another study showed similar result, and concluded that chronic hepatitis itself causes neuropsychiatric symptoms including cognitive decline and decline in QOL, and after starting IFN therapy these symptoms further deteriorated, however, it was not specified how much cognitive impairment was present before starting the treatment.

Therefore, they could not differentiate whether cognitive impairment was associated with Hepatitis C itself or started after initiation of IFN therapy.

In this study, we assessed cognitive impairment \& QOL at initiation of therapy and after 12 weeks of therapy [2].

Jaun Cordoba et al. found in their study that patients with chronic hepatitis or compensated cirrhosis showed a decrease in QOL, in spite of unimpaired neuropsychological tests.

Patients with decompensated cirrhosis exhibited a further decrease in QOL and neuropsychological abnormalities.

The decrease in QOL was associated with severity of liver failure, neuropsychological abnormalities or treatment with beta- blockers or diuretics.

In our study we took only those patients of Hepatitis $\mathrm{C}$ who were not in decompensated state. So not all patients needed beta - blockers hence no effect of beta blockers on quality of life was seen in our patients [3]. It was observed in our study that QOL was significantly decreased in both the groups. $\left(\mathrm{P}=0.000^{* *}\right)$.

The decrease in QOL in cases might be due to neurotoxic side effects of Peg-IFN and decrease in QOL in controls might be due to progression of Hepatitis, or patients not taking any definitive treatment for the illness.

It remains to be seen on long term follow up after cessation of Interferon therapy whether QOL improved or not. In another study done by Fontana RJ et al it was concluded that retreatment of prior nonresponders with Peg-IFN \& Ribavirin was not associated with objective evidence of cognitive impairment as measured by a comprehensive battery of neuropsychological tests.

Nonetheless, the frequency of cognitive impairment did not increase during the first 24 weeks of treatment in 177 patients $(\mathrm{P}=0.64)$.

In contrast our study showed significant decrease in cognitive functioning after 12 weeks. Foster GR, Goldin RD, Thomas HC.

(Chronic hepatitis $\mathrm{C}$ virus infection causes a significant reduction in quality of life in the absence of cirrhosis. Hepatology 1998; 27: 209-12) [4].

\section{Summary AND CONCLUSION}

This concludes that besides other known neuropsychiatric complications with Interferon there is a significant impairment in Cognitive functions and Quality of life in Hepatitis C patients on Peg-Interferon therapy from baseline to follow-up (12 weeks).

Impairment in cognitive function also affected the Global Assessment of Cognitive Function. It is also concluded that both the component of QOL i.e physical and psychological is decreased in maximum no. of Hepatitis C patients independent of effect of PegInterferon therapy.

Cognitive impairment may influence medical care, as cognitively impaired patient may fail to remember (or remember incorrectly) important details about their liver disease, treatment regimen, and psychiatric illness.

They may experience difficulties performing household and job duties as efficiently and accurately as before. Ultimately, many patients may experience frustration and mood problems, such as depression and anxiety, decrease in QOL which can exacerbate cognitive deficits.

Therefore QOL should be assessed in every Hepatitis C patient periodically irrespective of the treatment strategy. We suggest close monitoring of Cognitive Functions of Hepatitis $\mathrm{C}$ patients throughout the course of Peg- Interferon therapy. Cognitive impairment may influence medical care, as cognitively impaired patient may fail to remember (or remember incorrectly) important details about their liver disease, treatment regimen, and psychiatric illness.

They may experience difficulties performing household and job duties as efficiently and accurately as before. Ultimately, many patients may experience frustration and mood problems, such as depression and anxiety, decrease in QOL which can exacerbate cognitive deficits. 
Therefore QOL should be assessed in every Hepatitis C patient periodically irrespective of the treatment strategy. We suggest close monitoring of Cognitive Functions of Hepatitis $\mathrm{C}$ patients throughout the course of Peg- Interferon therapy.

\section{REFERENCES}

1. Cozolino LJ, Daniel J. Seigel. Contributions of the Psychological sciences: Sensations, Perception, Cognition. In: Sadock BJ, Sadock VA editors. Comprehensive Textbook of Psychiatry $8^{\text {th }}$ edition. Philadelphia: Lippincott, William and Wilkins. 2005: 521.

2. James M, Michael F. Schizophrenia. Cognition. In: Sadock BJ, Sadock VA editors. Comprehensive Textbook of Psychiatry $8^{\text {th }}$ edition. Philadelphia: Lippincott, William and Wilkins. 2005: 1437.

3. Davis KL. Cognitive Disorders. Introduction and overview. In: Sadock BJ, Sadock VA editors. Comprehensive Textbook of Psychiatry $8^{\text {th }}$ edition. Philadelphia: Lippincott, William and Wilkins. 2005: 1053.

4. World Health Organization. Quality of Life Assessment (WHO QOL) - Position Paper from World Organization. Social Science and Medicine. 1995; 10: 1403-09.

5. Kraus MR, Schafer A, Wibmann S, Reimer P, Scheurlen M. Neurocognitive Changes in patients with hepatitis $\mathrm{C}$ receiving interferon alfa-2b and ribavirin. Clinical Pharmacology \& Therapeutics. 2005; 77: 90-100.

6. Dieperink E, Willenbring $\mathrm{M}$ and Samuel B. Ho. Neuropsychiatric Symptoms Associated with Hepatitis C and Interferon Alpha: A Review. AM J Psychiatry. 2000; 157: 867-76.
7. Kraus MR, Schafer A, Faller H, Csef H, Scheurlen M. Psychiatric symptoms in patients with chronic hepatitis $\mathrm{C}$ receiving interferon alfa $2 \mathrm{~b}$ therapy. $\mathrm{J}$ Clin Psychiatry. 2003; 6: 708-14.

8. Córdoba J, Flavià M, Jacas C, Sauleda S, Esteban JI, Vargas V, Esteban R, Guardia J. Quality of life and cognitive function in hepatitis $\mathrm{C}$ at different stages of liver disease. Journal of hepatology. 2003 Aug 1;39(2):231-8.

9. Smith A, Tyrrell D, Coyle K. Higgins P. Effects of interferon alpha on Performance in man: a preliminary report Psychopharmacology (Berl). 1988; 96: 414-6.

10. Valentine A, Meyers C, Kling M, Richelson E, Hauser P: Mood and cognitive side effects of interferon- $\alpha$ therapy. Semin Oncol. 1998; 25(suppl (1): 39-47.

11. Fontana RJ, Bieliauskas L, Back-Madruga C, Lindsay KL, Litman HJ, Lok AS, Kronfol Z. Cognitive function does not worsen during longterm low dose peginterferon therapy in patients with chronic hepatitis C. The American journal of gastroenterology. $2010 \mathrm{Jul}$;105(7):1551.

12. Fontana RJ, Bieliaus LA, Lindsay K. Cognitive function does not worsen during Pegylated Interferon \& Ribavarine treatment of Chronic hepatitis C. Hepatology. 2000; 45(5): 1154-1163.

13. Lieb K, Engelbrecht M A, Gut O, Fiebich BL, Bauer J, Janssen G, Cognitive impairment in patients with chronic hepatitis treated with interferon alpha: results from a prospective study. European Psychiatry. 2006; 21: 204-10.

14. Fontana R J, Bieliauskas L a, Back-Madruga C, Lindsay K L, Litman H J, Lok A S. Cognitive function does not worsen during long-term lowdose Peg interferon therapy in patients with chronic hepatitis C. American J Gastroenterol. 2010; 105(7): 1551-60. 